\title{
The perils of partition: Difficulties in retrieving magma compositions from chemically equilibrated basaltic meteorites
}

\author{
Allan H. Treiman \\ Lunar and Planetary Institute, 3600 Bay Area Boulevard, Houston, TX 77058-1113, USA
}

(Received February 22, 1995; accepted in revised form October 17, 1995)

\begin{abstract}
The chemical compositions of magmas can be derived from the compositions of their equilibrium minerals through mineral/magma partition coefficients. This method cannot be applied safely to basaltic rocks, either solidified lavas or cumulates, which have chemically equilibrated or partially equilibrated at subsolidus temperatures, i.e., in the absence of magma. Applying mineral/ melt partition coefficients to mineral compositions from such rocks will typically yield "magma compositions" that are strongly fractionated and unreasonably enriched in incompatible elements (e.g., REEs). In the absence of magma, incompatible elements must go somewhere; they are forced into minerals (e.g., pyroxenes, plagioclase) at abundance levels far beyond those established during normal mineral/magma equilibria. Further, using mineral/magma partition coefficients with such rocks may suggest that different minerals equilibrated with different magmas, and the fractionation sequence of those melts (i.e., enrichment in incompatible elements) may not be consistent with independent constraints on the order of crystallization. Subsolidus equilibration is a reasonable cause for incompatibleelement-enriched minerals in some eucrites, diogenites, and martian meteorites and offers a simple alternative to petrogenetic schemes involving highly fractionated magmas or magma infiltration metasomatism.
\end{abstract}

\section{INTRODUCTION}

The compositions of basaltic magmas are among the best available constraints on the compositions of their parent planets and on petrogenetic processes within them (Drake, 1980). For bodies other than the Earth and Moon, basaltic meteorites are the only available basalt samples; however, meteorites are rarely large, commonly do not have bulk compositions representative of magma compositions, and commonly are brecciated into nonrepresentative fragments. Similarly, cumulate igneous rocks from all planets do not retain the compositions of their parent magmas. So there has been a strong impetus to derive the compositions of basaltic magmas from the compositions of mineral grains that crystallized from them. In the main, these efforts have been successful because of a strong database of experimental studies on the distributions of elements between magmas and minerals (e.g., Jones, 1995), and the development of extraordinarily sensitive analytical methods, e.g., secondary ion mass spectrometry (SIMS) and synchrotron X-ray fluorescence (SXRF).

A serious complication between a mineral analysis and the inference of its parental magma's composition is postmagmatic (subsolidus or metamorphic) redistribution of elements (Barnes, 1986a). A failure to recognize this process can lead to wildly erroneous estimates of trace element abundances in parent magmas, and thereby to completely unrealistic scenarios of magmatic and planetary evolution. The importance of subsolidus equilibration was first recognized by Consolmagno and Drake (1977), “. . . re-equilibration of the REE among phases means that attempts to calculate REE abundances in equilibrium with a single . . . phase will lead to erroneous conclusions . . .'. Subsolidus equilibration has been recognized in many relevant systems (e.g., Kennedy et al., 1992; Mittlefehldt et al., 1992; Fowler et al., 1994), but the character of the erroneous conclusions has not been explored.
In this work, I consider the effects of subsolidus equilibration on magma compositions inferred from mineral analyses, emphasizing rare earth element (REEs) distributions in simple basaltic systems. The derived principles are, however, relevant to all elements in all igneous rocks. First, I will explore the consequences of subsolidus equilibration on calculating magma compositions from a solidified basalt magma, then consider a basaltic cumulate, and finally reinterpret a few datasets from the literature.

\section{THEORY}

The partitioning of a trace element $Z$ between two phases, 1 and 2 , is commonly described by the equilibrium distribution coefficient $D$, the ratio of the mass concentrations of the element in the two phases at chemical equilibrium,

$$
D_{Z}^{1 / 2}=C_{Z}^{1} / C_{7}^{2}
$$

Nomenclature here follows Beattie et al. (1993). If the partition coefficient and the element concentration in one phase are known, then the element concentration in the other phase can be calculated. For instance, if 1 were pigeonite pyroxene and 2 were basalt magma, knowledge of $D_{\%}^{\text {pigetrite/hasalt }}$ would allow one to calculate the concentration of $\mathrm{Z}$ in the basalt from the concentration in its equilibrium pigeonite. More generally, consider a system of unit mass composed of phases, $1,2, \cdots$ $n$, in mass proportions $M_{1}, M_{2}, \cdots M_{n}$. For a trace element $\mathrm{Z}$ with total system abundance ( = concentration) $C_{Z}^{T^{\prime o t}}$, Eqn. 1 and mass balance on $Z$ yield:

$$
C_{Z}^{\mathrm{Tot}}=C_{Z}^{1} \cdot\left(M_{i}+\sum_{i=2}^{n} M_{i} \cdot D_{Z}^{i / 1}\right)
$$


If $C_{Z}^{\mathrm{T} \text { to }}$ and all $D$ and $M$ values are known, $C_{Z}^{\prime}$ can be calculated directly, and the concentrations of $Z$ in other phases can be calculated via Eqn. 1 .

These equations are most commonly applied to igneous systems; if one phase is a magma, Eqn. 2 describes the distribution of elements in batch melting or equilibrium crystallization. For example, consider the distribution of $\mathrm{La}$, a light (highly incompatible) rare earth element (LREE) in a eucrite basalt containing $C_{\mathrm{l} .1}^{\mathrm{Tot}}=10 \times \mathrm{CI}$. If the basalt contains $50 \%$ magma, 25\% pigeonite, and $25 \%$ plagioclase at chemical equilibrium, Eqn. 2 implies that $C_{\mathrm{L} . \mathrm{a}}^{\text {magma }}=19.6 \times \mathrm{CI}$, $C_{\mathrm{lia}}^{\text {pigenite }}=0.039 \times \mathrm{CI}$, and $C_{\mathrm{Ii}}^{\text {plapkelusi }}=0.82 \times \mathrm{CI}$, using the partition coefficients of Table 1. Magma is the main repository for highly incompatible elements like La.

\subsection{Subsolidus Equilibration}

In a basaltic rock that has chemically equilibrated at subsolidus temperatures (i.e., in the absence of magma), all elements must be sited in solid mineral phases. Elements that are not abundant enough to form separate minor phases (e.g., the REEs) will become distributed among the solid phases. The REEs are concentrated in phosphates relative to basalt magma (Table 1), and similarly relative to solid pyroxene and plagioclase (Tables 2,3). So the REE contents of individual phases in an equilibrated basalt depends on the bulk REE content and the mineral proportions. Other incompatible elements, like $\mathrm{Zr}$, may form a separate minor mineral, like zircon or baddeleyite. In this case, abundances of $\mathrm{Zr}$ in other minerals may reflect saturation in the minor mineral and be independent of the bulk $\mathrm{Zr}$ content (i.e., the original magma composition ).

To calculate the distribution of elements in a basaltic rock that has equilibrated subsolidus, one may apply Eqn. 2, which was constructed without prescience of the phases involved.

Table 1. REE Mineral/Basalt Partition Coefficients (D), see Equation 1.

\begin{tabular}{llllll}
\hline & pig/bas & pig/bas & aug/bas & pl/bas & wh/bas \\
\hline $\mathrm{La}$ & 0.002 & 0.001 & 0.03 & 0.042 & 25 \\
$\mathrm{Ce}$ & 0.004 & 0.004 & 0.04 & 0.03 & 25 \\
$\mathrm{Pr}$ & 0.012 & - & - & 0.025 & 25 \\
$\mathrm{Nd}$ & 0.019 & 0.010 & 0.10 & 0.02 & 25 \\
$\mathrm{Sm}$ & 0.031 & 0.042 & 0.17 & 0.0175 & 25 \\
$\mathrm{Eu}$ & 0.011 & -- & 0.11 & 1.2 & 23 \\
$\mathrm{Gd}$ & 0.043 & -- & 0.2 & 0.016 & 25 \\
$\mathrm{~Tb}$ & 0.055 & -- & 0.22 & 0.0095 & 25 \\
$\mathrm{Dy}$ & 0.07 & 0.070 & 0.24 & 0.0085 & 22 \\
$\mathrm{Ho}$ & 0.085 & -- & 0.25 & 0.008 & 19 \\
$\mathrm{Er}$ & 0.1 & 0.104 & 0.27 & 0.0075 & 15 \\
$\mathrm{Tm}$ & 0.115 & - & 0.28 & 0.007 & 11 \\
$\mathrm{Yb}$ & 0.13 & 0.129 & 0.29 & 0.0065 & 8 \\
$\mathrm{Lu}$ & 0.13 & -- & 0.30 & 0.0068 & 8 \\
\hline $\mathrm{Ref}$ & 1 & 2 & 1 & 3 & 4 \\
\hline
\end{tabular}

Basalt, bas; pigeonite, pig; plagioclase; augite, aug; whitlockite, wh.

1 McKay et al. (1986a).

2 Pun and Papike (1994).

3 From and extrapolated from Phinncy and Morrison (1990)

4 From and extrapolated from McKay et al. (1986b, 1987)

and McKay (priv. comm.)
Table 2: REE Mineral/Mineral Partition Coefficients (D) for Magmatic Temperatures.

\begin{tabular}{l|cccc}
\hline & pl/pig & pl/aug & pig/aug & wh/aug \\
\hline $\mathrm{La}$ & 21 & 1.4 & 0.067 & 830 \\
$\mathrm{Ce}$ & 7.5 & 0.75 & 0.10 & 625 \\
$\mathrm{Pr}$ & 2.1 & -- & -- & -- \\
$\mathrm{Nd}$ & 1.0 & 0.20 & 0.19 & 250 \\
$\mathrm{Sm}$ & 0.56 & 0.10 & 0.18 & 150 \\
$\mathrm{Eu}$ & 110 & 11 & 0.10 & 210 \\
$\mathrm{Gd}$ & 0.37 & 0.08 & 0.22 & 125 \\
$\mathrm{~Tb}$ & 0.17 & 0.040 & 0.25 & 113 \\
$\mathrm{Dy}$ & 0.12 & 0.035 & 0.29 & 92 \\
$\mathrm{Ho}$ & 0.09 & 0.032 & 0.34 & 76 \\
$\mathrm{Er}$ & 0.075 & 0.028 & 0.37 & 56 \\
$\mathrm{Tm}$ & 0.06 & 0.025 & 0.41 & 40 \\
Yb & 0.05 & 0.022 & 0.45 & 28 \\
$\mathrm{Lu}$ & 0.05 & 0.022 & 0.43 & 27 \\
\hline Calculated as quotients of values in Table \\
1. Mineral abbreviations as in Table 1.
\end{tabular}

To use Eqn. 2 for rocks equilibrated in the subsolidus, one needs mineral/mineral partition coefficients ( Tables 2,3). For magmatic and near-solidus temperatures, mineral/mineral partition coefficients can be estimated from mineral/magma coefficients. For minerals 1 and 2 :

$$
D_{\%}^{1 / 2}=\frac{D_{Z}^{1 / \text { magma }}}{D_{Z}^{2 / \text { magma }}}
$$

(see Eqn. 1), provided the mineral/magma coefficients have been determined for identical or similar chemical and physical conditions and are applied to systems with similar mineral compositions. Partition coefficients for lower temperatures can be calculated from analyses of coexisting phases in metamorphic rocks. Spot analyses (e.g., by focused beam instruments) are preferable, as whole mineral grains commonly contain inclusions of trace-element-rich materials. Electron microprobe analyses are abundant, but access only minor and the most abundant trace elements. Spot analyses by secondary ion mass spectrometry (SIMS) and synchrotron $\mathrm{X}$-ray fluorescence (SXRF) are relatively rare at this time, but can include the REEs. Analyses of mineral separates by neutron activation may include a wide suite of trace elements, but may be compromised by inclusions of other minerals (e.g., Bacon, 1989).

Mineral/mineral partition coefficients for magmatic conditions cannot be safely applied to subsolidus equilibria, because of differences in temperature and because of phase transformations. The dependencies of mineral $/$ mineral $D$ s on temperature have been explored in only a few systems, but $D$ values tend to become more extreme with decreasing temperature (Table 3; Kurat et al., 1980). For instance,

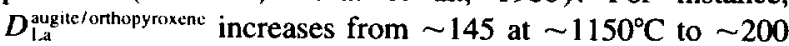
at $\sim 1050^{\circ} \mathrm{C}$ in terrestrial mantle xenoliths, based on mineral separates (Stosch, 1982).

$D$ values also vary with mineral composition (e.g., Coulson et al., 1988, 1989; Gallahan and Nielsen, 1992) and this variation undoubtedly extends to subsolidus equilibration. The effect of mineral composition on mineral/mineral Ds is most significant for pyroxenes, particularly the effect of their calcium content. Because $\mathrm{Ca}$ "opens" the pyroxene structure to 
permit the larger trace cations to enter (e.g., McKay et al., 1986a; Shearer et al., 1989), more calcic pyroxenes will tend to contain more of the REEs, especially LREEs (and Al, Ti, etc.). Thus, abundances of larger trace cations in pyroxenes will tend to be ordered $C_{z}^{\text {augite }}>C_{Z}^{\text {nigernite }}>C_{\%}^{\text {urthopyroxenc }}$ (Shearer et al., 1989), implying that $D_{\text {Lit }}^{\text {augite/pigesnite }}$

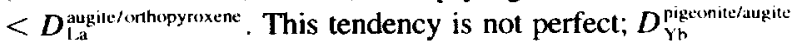
is $\sim 0.4$ under magmatic conditions (Table 2 ), and so is $D_{\text {Yb }}^{\text {anhonyroxene/augite }}$ in many metamorphically equilibrated eucrites and lunar samples (Table 3; Floss, 1991; Pun and Papike, 1995). Other compositional variables (e.g., Fe/Mg, $\mathrm{Al}$ and Ti content of pyroxene) may also affect $D$ values (Coulson et al., 1988, 1989; Gallahan and Nielsen, 1992).

\subsubsection{Example: Near-solidus equilibration of basalt}

Consider again a basalt rock (e.g., a eucrite) with $C_{\mathrm{REF}}^{\mathrm{Tot}}$ $=10 \times \mathrm{CI}$ (Fig. 1). If it equilibrated at a subsolidus but near solidus temperature, it might consist of $49.5 \%$ plagioclase, $49.5 \%$ pigeonite, $0.1 \%$ whitlockite (a $\mathrm{Ca}$ phosphate), and $0.9 \%$ minor phases with negligible REE abundances (e.g., silica, Fe metal, troilite); the exact mineral proportions are not critical. Figure 1 shows the REE contents of the basalt minerals, as calculated using the partition coefficients of Table 1 . The REE abundances in these pigeonite and plagioclase samples are much higher than those in equilibrium with basalt magma. In the example above of a basalt $\left(C_{\mathrm{REE}}^{\mathrm{Tat}}=10 \times \mathrm{CI}\right)$ with 50\% magma, one calculates $C_{\mathrm{LA}}^{\text {pigeonitc }}=0.04 \times \mathrm{CI}$ and $C_{\mathrm{La}}^{\text {plagiclase }}=0.8 \times \mathrm{CI}$; with no magma present, $C_{\mathrm{l} . \mathrm{a}}^{\text {pigeonite }}=0.4$ $\times \mathrm{CI}$ and $C_{\mathrm{La}}^{\text {plagioclase }}=9 \times \mathrm{CI}$. This tenfold enrichment in mineral REE abundances reflects the absence of magma. When magma is present, the magma is a major carrier of the REEs (and other incompatible elements); when magma is absent, the REEs must be accommodated by solid phases.

Calculation of the hypothetical "parent basalt" by mineral/ melt partition coefficients (Eqn. 1) is unjustified here, because

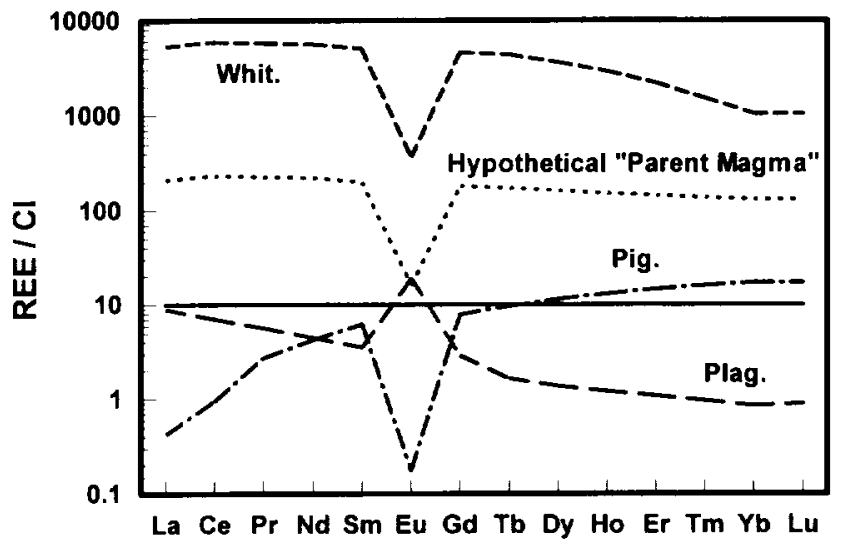

FIG, 1. Calculated REE abundances in minerals of a basalt equilibrated in the absence of magma just below its solidus temperature ( $D$ values of Table 2 ), and the hypothetical "parent magma" inferred by $D_{\mathrm{RH} \text { : }}^{\text {minal/hasal }}$ from those mineral compositions ( $D$ values of Table 1). See text for details of model. Whole-rock (heavy line) and equilibrium mineral compositions (Pig., pigeonite; Plag., plagioclase: Whit; whitlockite)

the calculation assumes that the minerals last equilibrated in the presence of a basaltic magma. Following this false assumption (using $D$ values of Table 1), one would infer a "parent basalt" with REE abundances as shown in Fig. 1. Because these same $D$ values were used to calculate the REE abundances in the minerals and the hypothetical magmas, all minerals in this rock appear to have equilibrated with the same "parent basalt,"

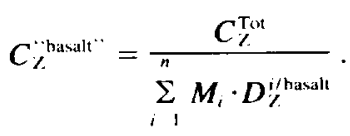

Table 3. Mineral/mineral Partition Coefficients (D) for Subsolidus Temperatures.

\begin{tabular}{|c|c|c|c|c|c|c|c|c|}
\hline & \multicolumn{2}{|c|}{ pl/opx } & $\mathrm{pl} / \mathrm{aug}$ & \multicolumn{4}{|c|}{ opx/aug } & \multirow{2}{*}{$\begin{array}{c}\text { wh/opx } \\
\text { Roda }\end{array}$} \\
\hline Sample & 76535 & 62255 & 62255 & 62255 & 60055 & Moama & UsMo & \\
\hline La & 150 & 7.5 & 0.52 & 0.07 & - & 0.010 & 0.005 & $500,000-1,500,000$ \\
\hline $\mathrm{Ce}$ & 30 & 3.6 & 0.23 & 0.06 & 0.006 & 0.008 & 0.005 & $150,000-1,000,000$ \\
\hline $\mathrm{Pr}$ & 12 & 17 & 0.11 & 0.07 & - & - & - & - \\
\hline Nd & 5.3 & 0.85 & 0.06 & 0.07 & 0.011 & 0.020 & 0.0075 & $\sim 10,000$ \\
\hline $\mathrm{Sm}$ & 1.4 & 0.31 & 0.02 & 0.08 & 0.007 & 0.042 & 0.016 & $\sim 10,000$ \\
\hline Eu & - & - & $11^{*}$ & - & - & 0.0006 & $0.022 \dagger$ & $\sim 85,000^{*}$ \\
\hline Gd & 0.46 & 0.13 & 0.013 & 0.11 & 0.04 & - & 0.027 & - \\
\hline $\mathrm{Tb}$ & 0.20 & 0.06 & 0.009 & 0.16 & 0.07 & 0.138 & 0.036 & - \\
\hline Dy & 0.1 & 0.03 & 0.006 & 0.19 & 0.12 & - & 0.048 & - \\
\hline $\mathrm{Ho}$ & 0.07 & 0.03 & 0.008 & 0.27 & 0.14 & - & 0.059 & - \\
\hline $\mathrm{Er}$ & 0.04 & 0.009 & 0.003 & 0.32 & 0.23 & 0.28 & - & - \\
\hline $\mathrm{Tm}$ & 0.03 & - & - & 0.38 & 0.32 & - & 0.12 & - \\
\hline $\mathrm{Yb}$ & 0.04 & 0.008 & 0.004 & 0.53 & 0.43 & 0.387 & 0.14 & - \\
\hline $\mathrm{Lu}$ & - & - & - & 0.71 & 0.46 & - & 0.19 & - \\
\hline Ref. & 1 & 1 & 1 & 1 & 1 & 2 & 3 & 4 \\
\hline $\begin{array}{l}\text { Mineral a } \\
1 \text { Derived } \\
2 \text { Pun and } \\
3 \text { Derived } \\
4 \text { Derived } \\
\text { Equilib }\end{array}$ & $\begin{array}{l}\text { abbreviatio } \\
\text { d from data } \\
\text { d Papike (1 } \\
\text { d from data } \\
\text { d from data } \\
\text { ration und }\end{array}$ & $\begin{array}{l}\text { as in Tab } \\
\text { n Floss (1 } \\
\text { 95). } \\
\text { n Stosch ( } \\
\text { n Mittlefe } \\
\text { reducing }\end{array}$ & $\begin{array}{l}1 \text {, and: o } \\
1) \text {. }\end{array}$ & hopyroxe & opx. & 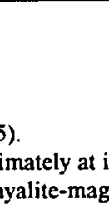 & . & \\
\hline
\end{tabular}


This hypothetical "parent basalt" (Fig. 1) has high overall abundances of the REE (130-200 $\times \mathrm{CI})$, moderate enrichment in light REEs $(\mathrm{La} / \mathrm{Lu}=1.6 \times \mathrm{CI})$, and strong depletion in Eu, relative to $\mathrm{Sm}$ and $\mathrm{Gd}$.

Why is this hypothetical "parent basalt" (Fig. 1) so different from the original simple basalt, with $C_{\mathrm{RtH}}^{\mathrm{T} \text { il }}=10 \times \mathrm{CI}$ ? The calculated Eu content of the "parent basalt" is similar to the original basalt, because $\mathrm{Eu}$ is partitioned into plagioclase in both subsolidus and super-solidus conditions. The remaining REEs, having no melt phase in which to reside, have been forced into solid phases; the rock contains so little whitlockite that the bulk of the REEs are in plagioclase and pigeonite. Thus, the plagioclase and pigeonite have been forced to accommodate far more of the REEs than they would have in the presence of magma. And a higher REE content in the plagioclase and pigeonite require a higher REE content in the inferred hypothetical "parent basalt."

Thus, the geochemist or petrologist will be grossly misled by assuming or inferring that the compositions of minerals in this rock reflect equilibrium with magma. The inferred hypothetical "parent basalt" has $\sim 20$ times the REE content of the original basalt, is moderately fractionated while the original basalt is not, and has a strong $\mathrm{Eu}$ anomaly which the original basalt does not (Fig. 1). Certainly, the petrogenesis of this hypothetical "parent basalt" would be fundamentally different from the petrogenesis of the original simple basalt.

\subsubsection{Example: Deep-subsolidus equilibration of basalt}

If this basalt rock equilibrated at a lower temperature, significantly below the solidus, the results of applying mineral/ melt REE partitioning might be still more extreme, as suggested by a comparison of solidus-temperature vs. subsolidus $D$ values ( Tables 2,3 ). The effects of subsolidus equilibration on inferred magma compositions can be seen by again considering a basalt with $C_{\mathrm{Rt}: \mathrm{F}}^{\mathrm{T}}=10 \times \mathrm{CI}$. If this basalt chemically equilibrates at deep-subsolidus temperatures (e.g., $700^{\circ} \mathrm{C}$ ), it might consist of $49.5 \%$ plagioclase, $44.5 \%$ orthopyroxene, $5 \%$ augite, $0.1 \%$ whitlockite, and $0.9 \%$ other phases (again, the phase proportions are not critical). The augite and orthopyroxene derive from inversion of the original magmatic pigeonite. REE abundances in these minerals, shown in Fig. 2a, are calculated from equation 2 and the $D_{\text {RrE. }}$ of Table 3. For consistency, I use the $D$ s for the lunar sample 62255, except for $D_{\mathrm{R}: \mathrm{H}}^{\text {whilk:kitc/augite }}$ which must be taken from Table 2 in the absence of an independent subsolidus estimate. Inverting those abundances to magma compositions ( $D$ values of Table 1 ), one finds that all the minerals would have formed from fractionated magmas much richer in REEs than the original bulk rock and magma (Fig. 2b).

In addition, each mineral would appear to have equilibrated with a different magma composition (Fig. 2b) except for whitlockite and augite. Whitlockite and augite would appear to have come from the same magma because the calculation had to rely on $D_{\mathrm{REE}}^{\text {whitkickite/augite }}$ for magmatic temperatures. The relative $\mathrm{REE}$ enrichments in these hypothetical parent magmas derive entirely from the different temperature dependencies of the $D$ values, and have nothing to do with magmatic processes.

For example, the order of increasing REE content of "parent magmas" could be wrongly construed as the order in which the minerals crystallized (in a fractionating system). Even though the plagioclase "parent magma" is poorer in REE than the pyroxene "parent magma" (Fig. 2b), plagioclase and pyroxene co-crystallize in the eucrite basalts on which this model was based. Looked at more quantitatively, the "parental magma" for plagioclase has roughly one-third the REE content of the "parent magma" for orthopyroxene. For closed system crystallization, this would imply crystallization of approximately two-thirds of the system as plagioclase before pyroxene began to crystallize. This inference must be wrong, as the system has only $49.5 \%$ plagioclase.

\subsubsection{Example: Subsolidus equilibration of a basaltic cumulate}

Cumulate igneous rocks do not (ipso facto) retain the compositions of their parent magmas, and so are natural targets for retrieving magma compositions by mineral/magma $D$ values. If the cumulate minerals have not chemically equilibrated at subsolidus temperatures, mineral/magma $D$ s are an effective indispensable tool in recovering magma compositions. If the cumulate minerals have chemically equilibrated in the absence of magma, application of mineral/magma $D$ values will again suggest incorrect compositions for parental magmas.

Consider as examples two nearly pure pigeonite orthocumulates. Let the first comprise $0.1 \%$ eucritic magma (REEs at $10 \times \mathrm{CI}$ ) and $99.9 \%$ pigeonite pyroxene that equilibrated with the magma; let the second comprise $1 \%$ eucritic magma and $99 \%$ pigeonite. Let these cumulates crystallize and chemically equilibrate as closed systems at temperatures just beneath the basalt solidus. After solidification, the first cumulate would contain $\sim 99.9495 \%$ pigeonite, $\sim 0.0495 \%$ plagioclase, $\sim 0.0001 \%$ whitlockite, and $\sim 0.0009 \%$ phases without significant REEs; the second cumulate would contain $\sim 99.495 \%$ pigeonite, $\sim 0.495 \%$ plagioclase, $\sim 0.001 \%$ whitlockite, and $\sim 0.009 \%$ phases without significant REEs.

Figure 3 shows the REE contents of "magmas" for these two cases calculated from pigeonite compositions and $D_{\mathrm{REE}}^{\text {pigeonitc/basall }}$ of Table 1 . In both cases, $0.1 \%$ parent magma and $1 \%$ parent magma, the HREE contents of the calculated "magmas" are within uncertainty of the true parent magma. But LREE abundances in the calculated "parent magmas" are significantly different. For the cumulate with $0.1 \%$ parent magma, the calculated "magma" appears to have La/Lu $=1.4 \times \mathrm{CI}$, which is only slightly above that of the true parent magma. Still, this elevated La/Lu would be sufficient to support hypotheses of fractionated parent magma or of magmatic infiltration metasomatism. For the cumulate with $1 \%$ parent magma, the calculated "magma" appears to be highly enriched in LREEs, with $\mathrm{La} / \mathrm{Lu}=4 \times \mathrm{CI}$. This strongly fractionated "magma" would imply a completely different petrogenesis than would the true eucritic parent magma.

\subsubsection{Conclusion}

Spectacular failure may attend the derivation of magma compositions from equilibrated rocks through application of mineral/melt partition coefficients. For basaltic systems, the derived magma compositions will be unnaturally enriched in incompatible elements and highly fractionated. Further, each 
(a)

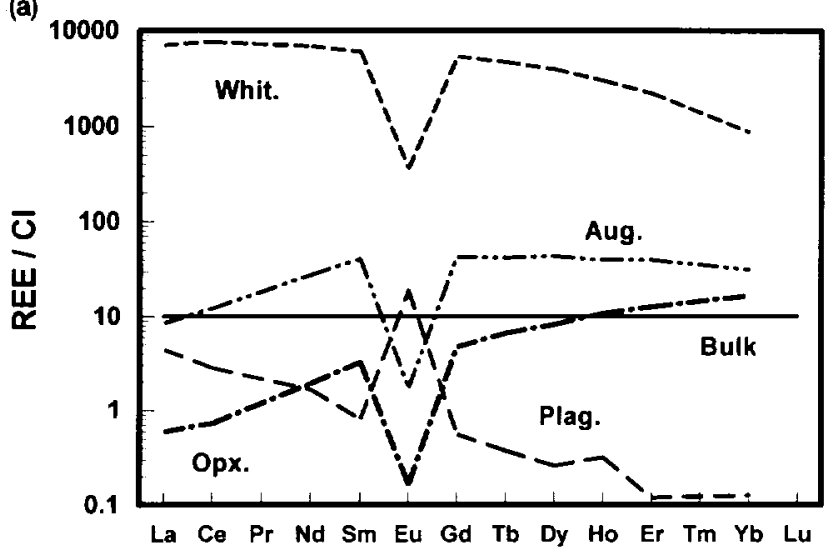

(b)

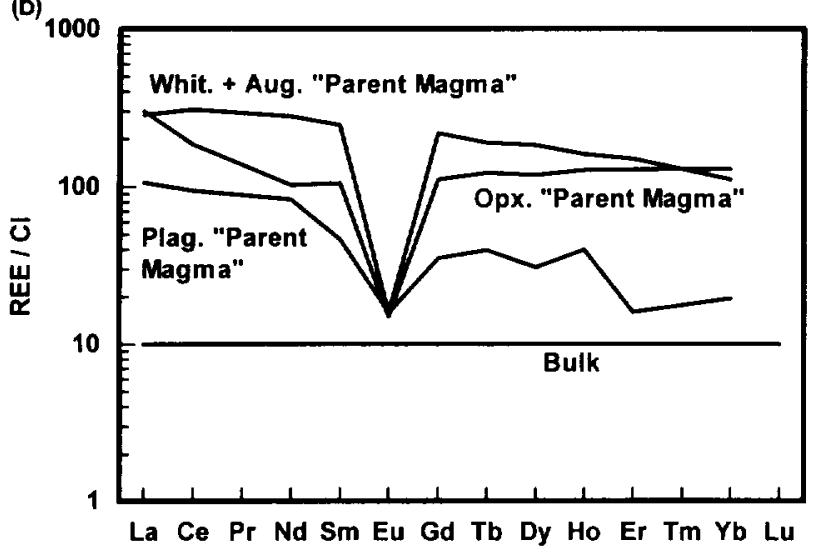

FIG. 2. Calculated REE abundances in minerals of a basalt equilibrated at a temperature far below its solidus, and inferred hypothetical "parent magma" compositions from those minerals. See text for details of model. (a) REE abundances in a basalt and its constituent minerals ( $D$ values of Table 3, except for $D_{\mathrm{kt}: \mathrm{l}}^{\text {thilkitc/augite }}$ and $D_{\mathrm{ku}}^{\text {auque/pigenite }}$ from Table 2). Whole rock (Bulk, heavy line) and equilibrium mineral compositions: Opx., orthopyroxene; Aug., augite; Plag., plagioclase; Whit, whitlockite. (b) REE abundances in hypothetical "parent magmas" inferred from mineral compositions of part a) and $D_{\mathrm{R}: \mathrm{l} \text { : }}^{\text {mincralhasilt }}$ of Table 1 . Whole rock (Bulk, heavy line) and hypothetical "magma" compositions in equilibrium with minerals: Opx. Magma, from orthopyroxene; Aug. + Whit. Magma, from augite and whitlockite; Plag. Magma, from plagioclase.

mineral may yield a different magma composition, depending on the mineral species and the temperature of equilibration. The inference of different magma compositions during the crystallization of the rock may lead to spurious conclusions about order of crystallization and causes for changing magma composition.

\section{EXAMPLES FROM THE LITERATURE}

As shown above, a failure to recognize subsolidus or metamorphic equilibration of trace elements can have dire geochemical consequences. A few cases from the literature will suffice as examples.

\subsection{Cumulate Eucrites}

Among the eucrite (basaltic) meteorites are a few cumulate lithologies, with relatively low REE abundances $(\sim 0.5-5$ $\times \mathrm{CI}$ ), Eu excesses, and depletions of LREEs (e.g., Dodd, 1981; Hamet et al., 1978). These characteristics suggest that the cumulate eucrites are plagioclase-pyroxene cumulates, but the REE characteristics of their parent magmas are in doubt (e.g., Consolmagno and Drake, 1977; Stolper, 1977; Hamet et al., 1978, Pun and Papike, 1995).

Many investigators have assumed or inferred that mineral compositions in the cumulate eucrites reflect mineral/magma equilibria, and so have inferred or suggested that their parental magmas were highly fractionated (Ma et al., 1977; Stolper, 1977; Ma and Schmitt, 1979; Pun and Papike, 1995; Hsu and Crozaz, 1995). However, the compositions of cumulate eucrite minerals probably reflect mineral/mineral, not mineral/ magma, equilibria (Schnetzler and Philpotts, 1969; Consolmagno and Drake, 1977; Treiman and Drake, 1985), and recent SIMS data show that REEs in their pyroxenes were redistributed at subsolidus temperatures (Pun and Papike, 1995).

For example, consider the Moore County cumulate eucrite. Figure 4 shows the REE contents of a Moore County plagioclase separate, the estimated average pyroxene (Schnetzler and Philpotts, 1969; Pun and Papike, 1995), and of hypothetical magmas in equilibrium with both minerals. These hypothetical magmas are strongly enriched in REEs and especially enriched in LREEs compared to normal eucrites (Fig. 4), as shown by Ma et al. (1977), Stolper (1977), Ma and Schmitt (1979), and Pun and Papike (1995). However, the REE patterns of the minerals and inferred magmas in Fig. 4 are qualitatively similar to those from equilibrated basaltic rock in Figs. 1 and 2. This suggests that the REE distribution between minerals reflects subsolidus equilibrium, as is consistent with the REE analyses and two-pyroxene thermometry of Pun and Papike ( 1995). The near-identity of the "magma" compositions inferred from plagioclase and pyroxene suggests that intergrain diffusion of REEs ceased at near-solidus temperatures, even though intragrain redistribution of REEs

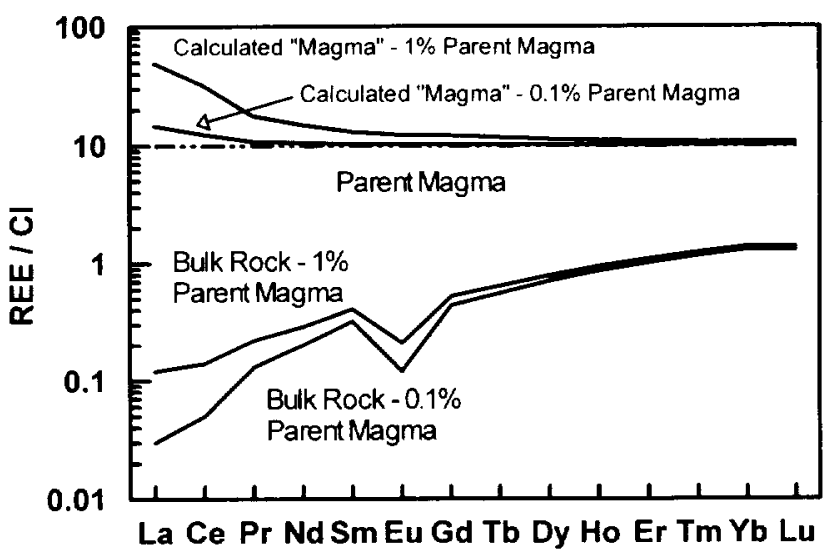

FiG. 3. Calculated REE abundances in two cumulates from a eucritic basaltic parent magma (REE at $10 \times \mathrm{CI}$ ): 1) $99 \%$ pigeonite and $1 \%$ parent magma; and 2) $99.9 \%$ pigeonite and $0.1 \%$ parent magma For each case, figure shows calculated composition of bulk cumulate and composition of "parent magma" calculated from chemically

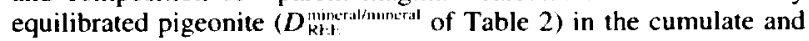
$D_{\mathrm{R}: 1}^{\mathrm{mun}}$ : 


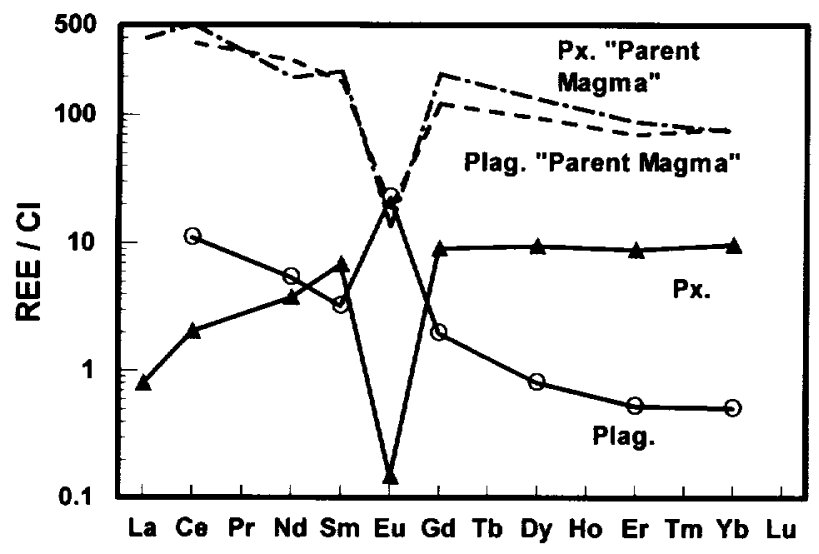

FIG. 4. REE abundances in Moore County minerals and inferred "parent magmas" ( $D$ values from Table 1$)$. Plag., plagioclase, open circles (Schnetzler and Philpotts, 1969); Px, pyroxene, filled triangles, (weighted average from analyses of Pun and Papike, 1995).

continued to much lower temperature (Pun and Papike, 1995).

\subsection{Diogenites}

The diogenite meteorites are orthopyroxenites with minor chromite and olivine, and are commonly interpreted as igneous cumulate rocks associated in some way with the eucrite basalts (Dodd, 1981; Mittlefehldt, 1994a; but see Jurewicz et al., 1995). Almost all have nearly homogeneous mineral compositions, and so are candidates for subsolidus chemical equilibration; Garland is the one exception, and Roda and Manegaon show considerable inter-grain chemical variations (Mittlefehldt, 1994a; Fowler et al., 1994, 1995). Within the candidate equilibrated diogenites, $\mathrm{Fe} / \mathrm{Mg}$ is effectively con- stant, and there are limited ranges in $\mathrm{Al}, \mathrm{Cr}, \mathrm{Ti}, \mathrm{Zr}$, and $\mathrm{REE}$ contents (Mittlefehldt, 1994a; Fowler et al., 1994, 1995). Equally important, their orthopyroxenes have nearly constant $\mathrm{Cr} / \mathrm{Al}$ abundance ratio (Fowler et al., 1994), which is not to be expected in a magmatic system crystallizing orthopyroxene \pm chromite (Barnes, 1986b; Coulson et al., 1988; Jurewicz et al., 1995). Thus, the homogeneity of $\mathrm{Fe} / \mathrm{Mg}$ and apparent nonigneous element distributions in diogenites (except Garland) suggest that subsolidus chemical equilibria was important.

\subsubsection{LREE-rich whitlockite}

In the Roda diogenite, Mittlefehldt (1994a) reported minute grains of REE-rich whitlockite with $\mathrm{La}=65,000 \times \mathrm{CI}$ $\left(1.8 \% \mathrm{La}_{2} \mathrm{O}_{3}\right)$ and $\mathrm{Sm}=6600 \times \mathrm{CI}\left(0.11 \% \mathrm{Sm}_{2} \mathrm{O}_{3}\right)$ by electron microprobe spot analysis (Fig. 5). If this whitlockite composition reflected equilibrium with a magma, it would have had $\mathrm{La} \cong 2600 \times \mathrm{CI}$ and $\mathrm{Sm} \cong 260 \times \mathrm{CI}(D$ values of Table 1). A similar REE-enriched phosphate, merrillite, is present in the Mt. Padbury mesosiderite, although chemical equilibrium among its phases is not complete (Kennedy et al., 1992).

However, the REE-enrichment of the Roda whitlockite could be a result of subsolidus chemical equilibrium with orthopyroxene. To test this interpretation, I will use $D_{\mathrm{REE}}^{\text {whillockite/orthopyroxene }}$ from subsolidus partition data, and com-

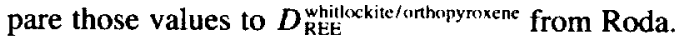

There is considerable uncertainty in $D_{\mathrm{REE}}^{\text {whillockite/orhupyroxenc }}$ from subsolidus data, because there appear to be no independent measurements of this mineral/mineral distribution coefficient. $D_{\mathrm{REE}}^{\text {whitlockite/orthupyroxene }}$ for subsolidus temperatures must be estimated as

$$
D_{\mathrm{REE}}^{\text {whitlockite/orthopyroxene }}=D_{\mathrm{REE}}^{\text {whillexkite/augite }} / D_{\mathrm{REE}}^{\text {onhopyroxene/augite }} \text {, }
$$

using the range of $D_{\mathrm{REE}}^{\text {inhopyraxenc/augite }}$ for subsolidus temperatures (Table 3 ) and the single value for $D_{R E E}^{\text {whitlockite/augite for }}$

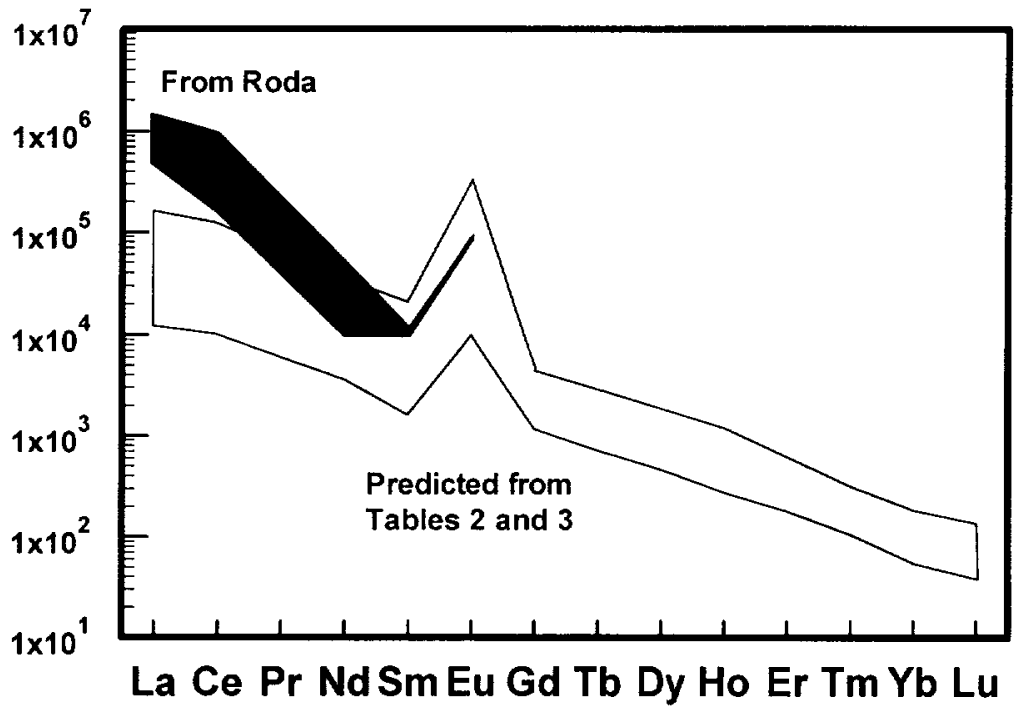

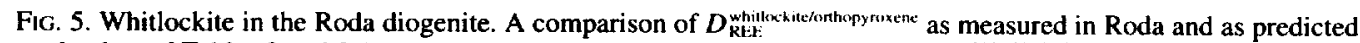

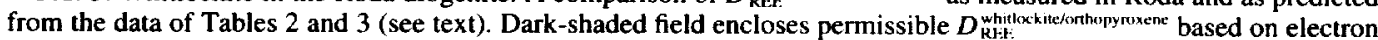
microprobe analysis of whitlockite in Roda and various SIMS and INAA analyses of Roda orthopyroxene (Mittlefehldt,

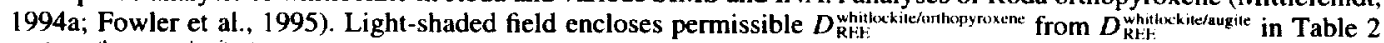
and $D_{\mathrm{R} P \mathrm{t}}^{\text {urthopyrexene/augite }}$ from Table 3. 
magmatic temperatures (Table 2). The REEs are predicted to be very strongly partitioned into whitlockite; the range of $D$ values is shown in Fig. 5.

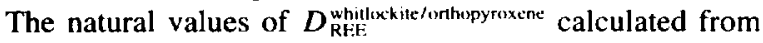
Roda must be limited to the light REEs ( $\mathrm{La}, \mathrm{Ce}, \mathrm{Nd}, \mathrm{Sm}, \mathrm{Eu}$ ) because heavier REEs were not be detected by EMP (Mittle-

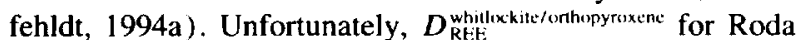
are uncertain because orthopyroxene adjacent to the whitlockite has not been analyzed, and because REE contents of Roda orthopyroxenes are quite variable (Fowler et al., 1995). Average SIMS analyses for Ce shows a large range, 0.058 to $0.34 \times \mathrm{CI}$ (Fowler et al., 1995), and the other LREEs are also variable: La ranges from $0.047 \times \mathrm{CI}$ (average SIMS spot analysis; Fowler et al., 1995 ) to $0.136 \times \mathrm{CI}$ (INAA analysis; Mittlefehldt, 1994a). Sm only ranges from $0.58 \times \mathrm{CI}$ (average SIMS spot analysis; Fowler et al., 1995) to $0.64 \times \mathrm{Cl}$ (INAA analysis; Mittlefehldt, 1994a). The Mittlefehldt (1994a) analyses, being on a chip sample, could have been compromised by inclusions of whitlockite. It is, of course, not known if the full range of orthopyroxene compositions have been sampled.

As shown in Fig. 3, the predicted $D_{\mathrm{RHF}}^{\text {whitlockilc/arthopyrexenc }}$ are

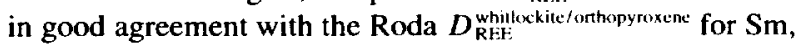
$\mathrm{Nd}$, and $\mathrm{Eu}$, but are an order of magnitude too low for La and Ce. Given the paucity of data and uncertainty about the REE content of orthopyroxene near the whitlockite, any number of hypotheses could explain the disagreement in Fig. 5 at La and Ce. Possibly, the whitlockite grew from a LREE-enriched "metasomatic" magma and never equilibrated with Roda pyroxenes (Wadhwa and Crozaz, 1994). Or, the orthopyroxene associated with the phosphate could be significantly richer in REEs than any Roda orthopyroxene analyzed so far. Or, the predicted $D_{\mathrm{Rl} \text { liti: }}^{\text {whickite/urthopyroxent }}$ for $\mathrm{La}$ and $\mathrm{Ce}$ could be too low, perhaps because the solidus-temperature $D_{\mathrm{REF}}^{\text {whitlix-kitc/augite }}$ cannot be safely extrapolated to subsolidus temperatures. I favor the last explanation, as the first two seem inconsistent with agreement between observed and predicted $D_{\mathrm{RHE}}^{\text {whithe-kite/orthopyrixem }}$ for $\mathrm{Sm}, \mathrm{Nd}$, and Eu. Thus, it seems reasonable to infer that REE abundances in Roda's whitlockite represent chemical equilibrium with adjacent orthopyroxene, and that Roda's whitlockite and orthopyroxene can be used as a preliminary calibration for subsolidus $D_{|: R|: \text { : }}^{\text {whitikitc/orthopyroxenc }}$ (Table 3 ).

\subsubsection{REE-rich plagioclase}

Plagioclase is rare in diogenites, but a few large grains have been recovered from the Johnstown diogenite by Mittlefehldt $(1979,1994 a)$. These plagioclases are rich in REEs and particularly the LREEs (e.g., $\mathrm{La}=\mathrm{Ce} \cong 20 \times \mathrm{CI}, \mathrm{La} / \mathrm{Sm} \cong 1.3$ $\times$ CI $)$. They were interpreted as having equilibrated with a magma that was highly enriched in the REEs, $\mathrm{La} \cong 270 \times \mathrm{CI}$, and strongly fractionated $\mathrm{La} / \mathrm{Sm} \cong 3-7 \times \mathrm{CI}$ (Mittlefehldt, 1979, 1994a). There is little other evidence for REE-enriched and fractionated magmas in diogenite petrogenesis, so Mittlefehldt $(1979,1994 \mathrm{a})$ suggested that the plagioclase grains might be exotic, and not related to the diogenite.

The constraints of subsolidus equilibration are consistent with the plagioclase grains being exotic, but not necessarily with their origin in a LREE-enriched magma. An exotic origin is likely because the plagioclase composition cannot reason- ably result from equilibration with a diogenitic parent magma (Mittlefelhdt, 1979) nor from subsolidus equilibration within a diogenite. To show the latter point, consider a diogenite consisting of $98 \%$ orthopyroxene, $0.5 \%$ plagioclase, and $1.5 \%$ other phases (chromite, troilite), with $\mathrm{La}=0.33 \times \mathrm{CI}$ and $\mathrm{Sm}=0.40 \times \mathrm{CI}$ (as does Johnstown; Mittlefehldt, 1994a). Using the plagioclase/orthopyroxene partition coefficients of Table 3 , the equilibrium plagioclase would have $\mathrm{La}=2.4$ $29 \times \mathrm{CI}$ and $\mathrm{La} / \mathrm{Sm}=25-30 \times \mathrm{Cl}$ (ranges reflect use of coefficients from samples 76535 vs. 62255 ). The predicted La abundances are consistent with the Johnstown plagioclase, but the predicted $\mathrm{La} / \mathrm{Sm}$ ratios are an order of magnitude too large. Impurities in the plagioclase sample will not help; pyroxene contains too little REEs, and whitlockite is likely to have La/Sm near $10 \times \mathrm{CI}$ ( see above; Mittlefehldt, 1994a).

However, the Johnstown plagioclase need not have formed in a LREE-enriched and fractionated magma; it could reasonably be a fragment from an equilibrated eucrite basalt. Eucritic fragments are present in other diogenites (Aioun el Atrouss, Garland, Pecklesheim: Delaney et al., 1983; Mittlefehldt, 1994a), and are not unexpected, as the HED meteorite breccias include the full range of mixtures of diogenitic and eucritic fragments (Delaney et al., 1983). The degree of fractionation of the Johnstown plagioclase $(\mathrm{La} / \mathrm{Sm}=1.3 \times \mathrm{CI}$ ) is similar to that of the calculated plagioclases in Figures 1 and $2 \mathrm{a}(\mathrm{La} / \mathrm{Sm}=2.5$ and 2 ), but its absolute REE abundances are higher. The difference in absolute REE abundances could reflect a different temperature of equilibration, a parent rock more enriched in REEs than the model, or traces of phosphate in the plagioclase. If the plagioclase sample of Fig. 2a contained $\sim 0.25 \%$ whitlockite, it would analyze at $\mathrm{La}=20$ $\times \mathrm{CI}$ and $\mathrm{La} / \mathrm{Sm}=1.4 \times \mathrm{CI}$, nearly identical to that of the Johnstown plagioclase.

\subsection{Martian Meteorites}

Twelve of the basaltic achondrite meteorites are almost certainly from Mars (McSween, 1994; Yanai, 1995; Mason, 1995). These martian meteorites have become indispensable in the current understanding of Mars, especially in Mars' igneous petrogenesis, and there is a great impetus to retrieve magma compositions from them (e.g., Stolper and McSween, 1979; Longhi and Pan, 1989; Treiman, 1993). However, most of the martian meteorites are crystal cumulates, and most of these have experienced some degree of subsolidus chemical equilibration (e.g., McSween, 1985; Treiman et al., 1994; Mittlefehldt, 1994b). For these equilibrated and partially equilibrated meteorites, one might assume that minerals retain their magmatic compositions, and thereby possibly fall into error.

\subsubsection{ALH8400I}

The ALH84001 meteorite is an orthopyroxenite, recently recognized by Mittlefehldt ( $1994 \mathrm{~b}$ ) as martian and not a diogenite. ALH84001 consists of approximately $97 \%$ orthopyroxene, $2 \%$ chromite, $1 \%$ maskelynite, and $0.15 \%$ phosphate (Dreibus et al., 1994; Wadhwa and Crozaz, 1994). The minerals in ALH84001 are essentially homogeneous in compo- 
sition (Mittlefehldt, 1994b; Papike et al., 1994), excepting those in the postigneous carbonate-rich alteration assemblage.

Despite the chemical homogeneity of the minerals in ALH84001, the REE contents of parent magmas have been calculated from mineral/melt partition coefficients and SIMS analyses of minerals (Papike et al., 1994; Wadhwa and Crozaz; 1994). Orthopyroxene was inferred to have equilibrated with a magma that was slightly depleted in LREEs compared to HREEs (with HREEs 10 $\times \mathrm{CI}$, Papike et al., 1994). Wadhwa and Crozaz (1994) further inferred that plagioclase and phosphate in ALH84001 equilibrated with magmas that were strongly enriched in REEs overall and especially the LREEs, and postulated that ALH84001 was infiltrated during late crystallization by very highly fractionated magmas.

Available evidence suggests, however, that REEs in ALH84001 minerals were affected by subsolidus equilibration, and cannot be used safely to infer magma compositions or magmatic processes. As noted above, minerals in ALH84001 are effectively homogeneous. Further, it appears likely that REE distributions in the ALH84001 minerals reflect subsolidus equilibria. From the limited data in Wadhwa and Crozaz (1994), one can calculate some REE distribution values for ALH84001 and compare them with the equilibrium values of Table 3. The data of Wadhwa and Crozaz (1994)

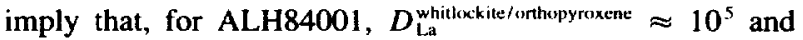
$D_{\mathrm{Lu}}^{\text {whitlockite/urthupyruxene }} \approx 15$; these values are comparable to (though slightly more extreme than) the equilibrium values of Tables 2 and 3 and Fig. 5. The Wadhwa and Crozaz (1994) analyses of maskelynite also imply $D_{-4}^{\text {plagiolase/orthopyroxene }} \approx 75$, in the range of subsolidus equilibrium values of Table 3 (it is possible, however, that the analyzed maskelynite was contaminated with shocked mesostasis material, which could be rich in REEs). Thus, one may credibly hypothesize that the observed REE distributions within ALH84001 reflect subsolidus equilibria, and have no significance for magma compositions or magmatic processes.

\section{AVOIDING PERIL: RECOGNIZING SUBSOLIDUS EQUILIBRATION}

As shown, applying mineral/magma partition coefficients to chemically equilibrated rocks can yield unrealistic magma compositions. So, how can one avoid this peril? How can one recognize rocks (or minerals) which might have experienced subsolidus equilibration?

The most general warning sign of subsolidus chemical equilibration in an igneous rock is homogeneous mineral compositions, because extensive subsolidus equilibration will erase any chemical zoning imposed during igneous fractionation. However, homogeneous mineral compositions do not necessarily require subsolidus equilibration. Crystals may have grown in a magma chamber so large and well-stirred that their growth did not fractionate the magma significantly. Or, diffusion may be so rapid (e.g., Fe, $\mathrm{Mg}$ in olivine) or crystallization times so long (e.g., deep plutonic settings) that minerals may continuously equilibrate with a fractionating magma. In the latter case, however, one might expect subsolidus cooling to be as protracted as the igneous cooling, and thus expect that subsolidus chemical effects might be significant.
Even if minerals are chemically zoned, they may still have been significantly affected by subsolidus chemical equilibration. One might suspect subsolidus equilibration if the zoning is monotonic, and especially if the zoning is not consistent with igneous fractionations. Monotonic zoning itself (e.g., consistently increasing $\mathrm{Fe} / \mathrm{Mg}$ from core to rim of a pyroxene) is not diagnostic, because it can develop during igneous fractionation as well as during metamorphic equilibration. However, fine-scale oscillatory zoning does not develop during metamorphism, and can be taken as prima facie evidence that igneous compositions are retained (e.g., Treiman and Essene, 1985 ). Second, any chemical zoning must be consistent with igneous fractionation patterns, i.e., mineral/magma distribution coefficients. Consider, for instance, a basaltic magma crystallizing pyroxene and olivine. Chromium is compatible in pyroxene $(D>1)$ and $\mathrm{Al}$ is incompatible $(D<1)$; neither element enters olivine significantly. Thus, the $\mathrm{Cr} / \mathrm{Al}$ ratio in the crystallizing pyroxene should decrease as pyroxene grows, as is seen in experimental studies of eucrite and diogenite genesis (e.g., Jurewicz et al., 1995). In such a basaltic rock, pyroxenes with constant $\mathrm{Cr} / \mathrm{Al}$ should be viewed with a suspicion of subsolidus equilibration.

On the other hand, magma compositions inferred from mineral/magma distribution coefficients can point to subsolidus chemical equilibration. Minerals affected by subsolidus chemical equilibration will tend to imply highly fractionated magma compositions, with high abundances of incompatible elements. Inference of such a fractionated evolved magma, in a setting where depleted or primitive magmas should prevail, should raise the specter of subsolidus chemical equilibration. Another related clue to subsolidus equilibration is that different minerals may imply different magma compositions, unrelated to order of crystallization (e.g., Fig. 2).

Thus, the details of mineral chemistry and the appropriateness of inferred magma compositions may provide important clues to whether an igneous rock has experienced significant subsolidus equilibration. If there is evidence of significant subsolidus equilibration, calculation of magma compositions

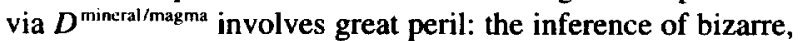
fractionated magmas from rocks that formed from common, simple magmas.

Note Added in Proof: REE abundances in mineral separates from the equilibrated eucrites Stannern and EET79002 conform to the predictions of section 2.1, as do their "parent magmas" calculated by $D^{\text {mineral/basalt }}$ (Phinney et al., 1993). Phinney W. C., Lindstrom D. J., Mittlefehldt D. W., and Martinez R. R. (1993) Post-igneous redistribution of components in eucrites. Lunar Planet. Sci. XXIV, 1137-1138 (abstr.).

Acknowledgments-I am grateful to $M$. Drake, who supported my early work on metamorphism of meteoritic basalts, and to J. Jones and $D$. Mittlefehldt for continuing dialogues on basalt petrology. Constructive and perceptive reviews by J. Jones, J. Longhi, D. Mittlefehldt, R. Nielsen, and G. Ryder are appreciated. This work is Lunar and Planetary Institute contribution $\$ 868$.

Editorial handling: M. Menzies

\section{REFERENCES}

Bacon C. R. ( 1989) Crystallization of accessory phases in magmas by local saturation adjacent to phenocrysts. Geochim. Cosmochim. Acta 53, $1055-1066$. 
Barnes S. J. (1986a) The effect of trapped liquid crystallization on cumulus mineral compositions in layered intrusions. Contrib. Mineral. Petrol. 93, 524-531.

Barnes S. J. ( 1986b) The distribution of chromium among orthopyroxene, spinel, and silicate liquid at atmospheric pressure. Geochim. Cosmochim. Acta 50, $1889-1909$

Beattie P. et al. (1993) Terminology for trace element partitioning. Geochim. Cosmochim. Acta 57, $1605-1606$.

Consolmagno G. J. and Drake M. J. ( 1977) Composition and evolution of the eucrite parent body: evidence from rare earth elements. Geochim. Cosmochim. Acta 41, 1271-1282.

Coulson R. O., McKay G. A., and Taylor L. A. ( 1988 ) Temperature and composition dependencies of trace element partitioning: Olivine/melt and low-Ca pyroxene/melt. Geochim. Cosmochim. Acta $52,539-553$.

Coulson R. O., McKay G. A., and Taylor L. A. (1989) Charge balancing of trivalent trace elements in olivine and low-Ca pyroxene: A test using experimental partitioning data. Geochim. Cosmochim. Acta 53, 643-648.

Delaney J. S., Takeda H., Prinz M., Nehru C. E., and Harlow G. E. (1983) The nomenclature of the polymict basaltic achondrites. Meteoritics 18, 103-111.

Dodd R. T. (1981) Meteorites A Petrologic-Chemical Synthesis. Cambridge Univ. Press

Dreibus G., Burghele A., Jochum K. P., Spettel B., Wlotzka F., and Wänke H. (1994) Chemical and mineral composition of ALH84001: A martian orthopyroxenite. Meteoritics 29, 461 (abstr.).

Drake M. J. ( 1980) Trace elements as quantitative probes of differentiation processes in planetary interiors. Rev. Geophys. Space Phys. 18, 11-26.

Floss C. (1991) Rare earth and other trace element microdistributions in two unusual extraterrestrial igneous systems: The enstatite achondrite (aubrite) meteorites and the lunar ferroan anorthosites. Ph.D. Thesis., Washington Univ., St. Louis, MO

Fowler G. W., Papike J. J., Spilde M. N., and Shearer C. K. (1994) Diogenites as asteroidal cumulates: Insights from orthopyroxene major and minor element chemistry. Geochim. Cosmochim. Acta 58, 3921-3929.

Fowler G. W., Shearer C. K., Papike J. J., and Layne G. D. ( 1995) Diogenites as asteroidal cumulates: Insights from orthopyroxene trace element chemistry. Geochim. Cosmochim. Acta 59, 3071-3084

Gallahan W. E. and Nielsen R. L. (1992) The partitioning of Sc, V. and the rare earth elements between high-Ca pyroxene and natural mafic to intermediate lavas at 1 atmosphere. Geochim. Cosmochim. Acta 56, 2387-2404.

Hamet J., Nakamura N., Unruh D., and Tatsumoto M. ( 1978) Origin and history of the adcumulate eucrite Moama as inferred from REE abundances, $\mathrm{Sm}-\mathrm{Nd}$ and $\mathrm{U}-\mathrm{Pb}$ systematics. Proc. 9th. Lunar Planet. Sci. Conf. 1115-1136.

Hsu W. and Crozaz G. (1995) Trace element distributions in single grains and the origin of eucrites. Meteoritics 30, 522. (abstr.).

Jones J. H. ( 1995 ) Experimental Trace Element Partitioning. In Rock Physics and Phase Relations: A Handbook of Physical Constants (ed. T. J. Ahrens), Chap. 7, pp. 73-104. AGU.

Jurewicz A. J. G., Mittlefehldt D., and Jones J. H. ( 1995) Experimental partial melting of the St. Severin (LL) and Lost City (H) chondrites. Geochim. Cosmochim. Acra 59, 391-408.

Kennedy A. K., Stewart B. W.. Hutcheon I. D., Papanastassiou D. A., and Wasserburg G. J. (1992) Partitioning of REE between phosphates and silicates in mesosiderites: Evidence for differing degrees of equilibration. Lunar Planet. Sci. XXIII, 681-682 (abstr.).

Kurat G. et al., (1980) Geochemistry of ultramafic xenoliths from Kapfenstein, Austria: Evidence for a variety of upper mantle processes. Geochim. Cosmochim. Acta 44, 45-60.

Longhi J. and Pan V. (1989) The parent magmas of the SNC meteorites. Proc. 19th Lunar Planet. Sci. Conf., 451-464.

Ma M.-S. and Schmitt R. A. (1979) Genesis of the cumulate eucrites Serra de Magé and Moore County: A geochemical study. Meteroritics $14,81-88$

Ma M.-S., Murali A. V., and Schmitt R. A. (1977) Genesis of Angra dos Reis and other achondritic meteorites. Earth Planet. Sci. Lett. 35, $331-346$.
Mason B. (1995) QUE94201 Antarctic Meteorite Newslett. 18, 25. McKay G. A.. Wagstaff J., and Yang S.-R. (1986a) Clinopyroxene REE distribution coefficients for shergottites: The REE contents of the Shergotty melt. Geochim. Cosmochim. Acta 50, 927-937.

McKay G., Le L., Wagstaff J., and Yang S.-R. (1986b) Whitockite/ melt partitioning and Shergotty chronology. Meteoritic: 21,448 449 (abstr.).

McKay G., Wagstaff J., Le L., and Lindstrom D. (1987) Whitlockite/ melt partitioning and Henry's Law: Shergotty late-stage minerals. Lunar Planet. Sci. XVIII, 625-626 (abstr.).

McSween H. Y. ( 1985 ) SNC meteorites: Clues to martian petrologic evolution? Rev. Geophys. 23, 391-416.

McSween H. Y. (1994) What we have learned about Mars from SNC meteorites Meteoritics 29,755-779

Mittlefehldı D. W. (1979) Petrographic and chemical characterization of igneous lithic clasts from mesosiderites and howardites and comparison with eucrites and diogenites. Geochim. Cosmechim. Acta 43, 1917-1935

Mittlefehldt D. W. ( 1994a) The genesis of diogenites and HED parent body petrogenesis. Goochim. Cosmochim. Acta 58, 15.37-1552.

Mittlefehldt D. W. ( 1994b) ALH 84001, a cumulate orthopyroxenite member of the martian meteorite clan. Meteoritic s 29, 214-221

Mittlefehldt D. W., Rubin A. E., and Davis A. M. (1992) Mesosiderite clasts with the most extreme positive europium anomalies among solar system rocks. Science 257, 1096-1099.

Papike J. J., Fowler G. W., Layne G. D., Spilde M. N., and Shearer C. K. (1994) ALH 84001 a "SNC orthopyroxenite": Insights from SIMS analysis of orthopyroxene and comparisons to diogenites. Lunar Planet. Sici. XXV, $1043-1044$ (abstr.).

Phinney W. C. and Morrison D. A. (1990) Partition coefficients for calcic plagioclase: Implications for Archean anorthosites. Geochim. Cosmochim. Acta 54, 1639-1654.

Pun A. and Papike J. J. ( 1994 ) The Pasamonte unequilibrated eucrite Pyroxene REE systematics and major-, minor-, and trace-element zoning (abstract). Meteoritics 29, 520-521.

Pun A. and Papike J. J. ( 1995 ) Ion microprobe investigation of exsolved pyroxenes in cumulate eucrites: Determination of selected trace element partition coefficients. Geochim. Cosmochim. Acto 59, 2279-2289.

Schnetzler C. C. and Philpotts J. A. (1969) Genesis of the calciumrich achondrites in light of rare-earth and barium concentrations. In Meteorite Research (ed. P. M. Millman),pp. 206-216. D. Reidel.

Shearer C. K., Papike J. J., Simon S. B., and Shimizu N. (1989) An ion microprobe study of the intra-crystalline behavior of REE and selected trace elements in pyroxene from mare basalts with different cooling rates and crystallization histories. Gerochim. Cosmochim. Acsa 53, 1041-1054

Stolper E. (1977) Experimental petrology of eucrite meteorites. Geochim. Cosmochim. Acta 41, 587-611

Stolper E. and McSween H. Y.. Jr. (1979) Petrology and origin of the shergottite meteorites. Geochim. Cosmochim. Acta 43, 1475-1498.

Stosch H.-G. ( 1982) Rare earth element partitioning between minerals from anhydrous spinel peridotite xenoliths. Geochim. Cosmochim. Acta 46, 793-811.

Treiman A. H. (1993) The parent magma of the Nakhla (SNC) meteorite, inferred from magmatic inclusions. Goochim. Cosmochim. Acta 57, 4753-4768.

Treiman A. H. and Drake M. J. (1985) Basaltic volcanism on the eucrite parent body: Petrology and chemistry of the polymict eucrite ALHA80102. Proc. 15th Lunar Planet. Sci. Conf.: J. Geophys. Res. 90 suppl., C619-C628

Treiman A. H. and Essene E. J. ( 1985 ) The Oka carbonatite complex, Quebec: Geology and evidence for silicate-carbonate liquid immiscibility. Amer. Mineral. 70, 1101-1113.

Treiman A. H. et al. (1994) Comparison of the LEW88516 and ALHA77005 martian meteorites: Similar but distinct. Meteoritic: 29, $581-592$

Wadhwa M. and Crozaz. G. (1994) First evidence for infiltration metasomatism in a Martian meteorite. ALH84001. Meteoritics 29. 545 (abstr.)

Yanai K. (1995) Re-searching for martian rocks from diogenite-diogenitic anchondrites. Lunar Planet. Si $i$. XXVI, 1533-1534 (abstr.) 
